\title{
Establishing good dietary habits - capturing the minds of children
}

\author{
Joachim Westenhoefer* \\ University of Applied Sciences, Department of Nutrition and Home Economics, Nutrition and Health Psychology \\ Group, Lohbruegger Kirchstr. 65, 21033 Hamburg, Germany
}

\begin{abstract}
Objective: To review the psycho-social research with respect to relevance for the development of nutritional education strategies.

Results: The eating behaviour of the newborn baby is controlled by innate preferences and dislikes, and by biological self-regulation. These innate controlsystems are modified by learning processes, most importantly by the mere exposure to unknown food, by social influences, and by associating the physiological consequences of food intake with taste cues. The last decades have witnessed a change of the social meaning of food and eating, and the social context of eating is subject to dramatic changes. While on the one hand, prevalence of overweight and obesity is increasing, even young children deliberately practise weight control measures ranging from selective food choice to self-induced vomiting thus including behaviours which are clearly symptomatic of eating disorders. Such behaviour is motivated by unrealistic conceptions of a healthy body weight and shape. Children are interested in a range of nutrition topics. However, these topics have to be related to direct perceivable benefits from nutrition.

Conclusions: Educational strategies should: firstly, focus on providing a variety of foods, including a range of nutrient-dense 'healthy' food and encouraging children to taste it; secondly, provide a stable and predictive pattern of social eating occasions to promote the social meaning and importance of eating and to enable social learning of food preferences; and finally, encourage a positive body image by providing advice and reassurance regarding the range of healthy and acceptable body weights and shapes.
\end{abstract}

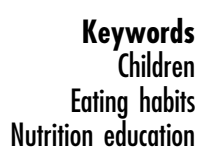

\section{Development of eating habits}

The newborn baby shows innate preferences for sweet tastes and innate dislikes for sour or bitter tastes ${ }^{1,2}$. From an evolutionary perspective these innate acceptance patterns serve as important biological functions, since in nature sweetness is associated with readily available calories from carbohydrates, and bitterness is correlated with toxicity ${ }^{3}$. Also, more directly, the innate preference for the sweet taste may reinforce breast milk consumption in the newborn baby. Additionally, the classic work of Clara Davis ${ }^{4,5}$, in which children self-selected a healthy diet without being influenced by adults, points to the possibility that human infants possess a biological control system which enables nutritionally adequate food choice, at least when a variety of wholesome and natural foods is available. However, it is not known whether this is also the case when more energy dense and processed foods become available. Nevertheless, these findings show that human food intake at the beginning of life is at least partially controlled by both biological systems and internal cues.

From the very beginning these innate preferences are modified by learning processes. Subsequently learning plays a major role in the development of food preferences and food rejections ${ }^{3,6}$. Three major processes have been described that modify food acceptance patterns of the child:

(1) The mere exposure to unknown food, i.e. the repeated experience of tasting and eating it, reduces the tendency to reject the unknown food, a phenomenon which has been termed neophobia ${ }^{6}$. Consequently, the preference for initially novel food increases with exposure, in children ${ }^{7}$ as well as in college students ${ }^{8}$. 


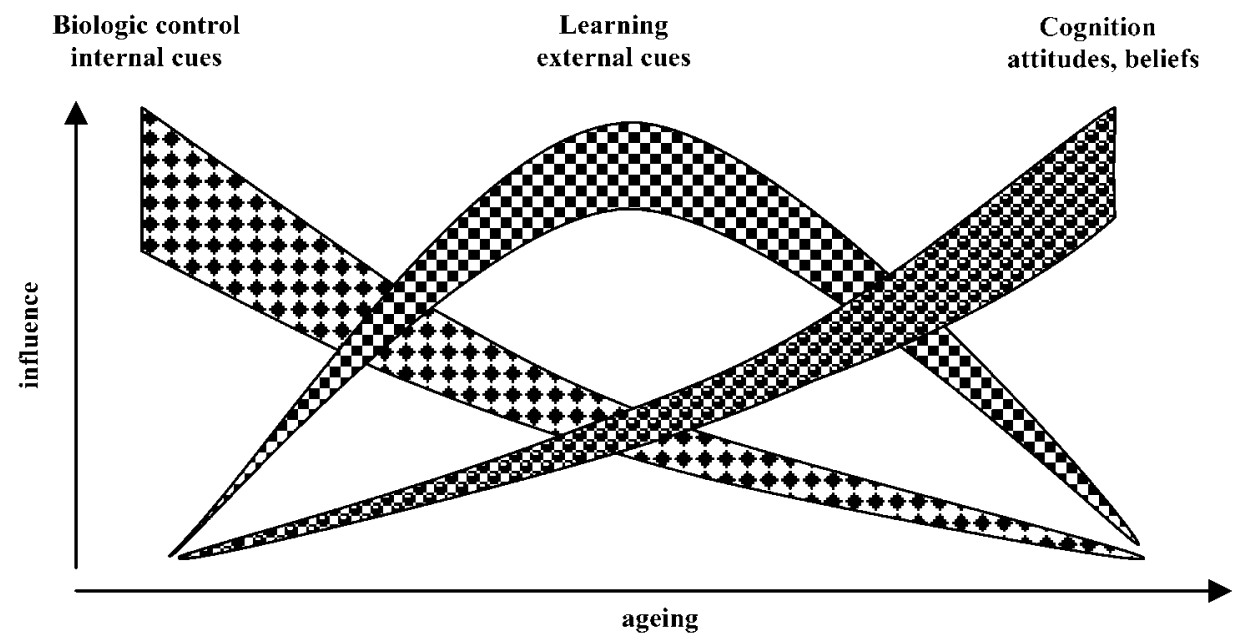

Fig. 1 Three component model of the development of human intake control (modified from Pudel, $1986^{13}$ )

(2) Food acceptance is modified by social influences: children learn to prefer food eaten by adults, by their peers or by fictional heroes in a story'. Peer influence may be even more influential than parental influence and has been shown to be effective in preschoolers $^{9,10}$.

(3) Children learn to associate the physiological consequences of food intake with taste cues from the food $^{11,12}$. These learning processes eventually result in cognitive structures and processes such as attitudes and beliefs about food and eating, which play an important role in the control of food intake in adults $^{13}$. A model of the relative importance of these factors over the life span is illustrated in Fig. 1.

\section{Global trends in the affective response to food}

Food acceptance and eating habits are of course influenced by global societal trends. These societal changes are relayed to children through social influences by parents, peers and the media. The last decades have witnessed a change of the social meaning of food and eating, which has brought about some affective alienation to food and eating ${ }^{14}$ :

- Value of food: the overabundance of food has changed its value. Younger generations lacking the direct experience of food scarcity will not value food in the same extraordinary way as previous generations.

- Identity of food: The development of modern distribution and marketing systems presents food in a way very similar to non-food products. This may contribute to the perception of food as any consumer good without distinguishing emotional attributes.

- Consciousness about its origin: Previous generations had more direct or indirect experience of food production. For example, in the late $19^{\text {th }}$ century more than $80 \%$ of the food consumed was produced within the household ${ }^{15}$. In contrast, today one would not necessarily associate a hamburger with a cow on the pasture-ground.

- Seasonal and regional characteristics: Modern transportation and distribution systems have made nearly any food from all over the world available at any time. This contributed to better nutrition by abandoning seasonal and regional limitations in food supply; however, the emotional attributes of the own regional cuisine or the special experiences, e.g. tasting the first fresh strawberries of the season, have diminished.

- Social context: Perhaps most importantly, the social context of eating is subject to dramatic changes. While in the past eating has always been within a social context, today eating alone has become a prevalent event. The consequences of this development are highlighted by the findings of a recent survey on eating habits and attitudes of 551 school children between 7 and 16 years in Hamburg (Germany) ${ }^{16}$. This survey identified that the importance of the family being present at meals has continuously decreased with age. In parallel the importance of watching television while eating increased with age. Thus, it appears that the family is replaced by the TV as 'social company' during meal times (see Fig. 2).

\section{Weight control}

The last decades have witnessed an alarming increase in the prevalence of both overweight and obesity in children ${ }^{17}$. However, even children as young as 9 years are dissatisfied with their body shapes even though they are at normal weight. Thus, they have higher levels of 


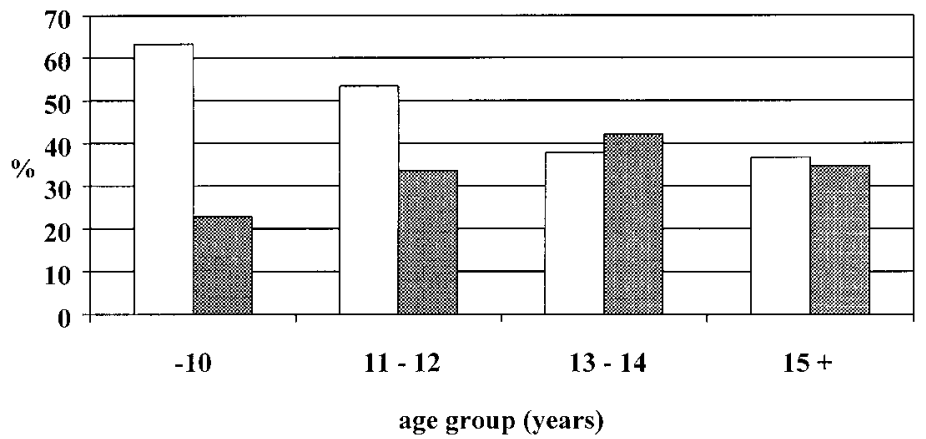

Fig. 2 Percentage of German school-children rating the family being present at meals (open bars) or watching TV at meals (filled bars) as important ${ }^{16}$

Table 1 Percentage of 7-16 year old school children using different measures to influence body weight ('What are you doing to influence your body weight?' - Multiple answers allowed) ${ }^{16}$

\begin{tabular}{lcr}
\hline & \multicolumn{2}{c}{ Responses (\%) } \\
\hline & Boys & Girls \\
I eat a lot of fruits and vegetables & 47.7 & 61.7 \\
I exercise & 55.1 & 45.4 \\
I eat light products & 11.3 & 8.9 \\
I deliberately eat less than I want & 18.0 & 27.5 \\
I skip meals & 11.3 & 27.5 \\
I avoid products with sugar & 15.2 & 22.7 \\
I go on diets & 9.0 & 20.8 \\
I eat low fat & 14.1 & 17.8 \\
I vomit after eating & 0.8 & 3.7 \\
I deliberately eat protein rich & 11.7 & 5.9 \\
I deliberately eat more than I want & 10.2 & 4.8 \\
I do nothing & 23.4 & 22.7 \\
\hline
\end{tabular}

dietary restraint, i.e. they are deliberately trying to restrict food intake in order to either lose or maintain weight ${ }^{18}$. In a survey of over 500 school children in Hamburg ${ }^{16}$ it was found that only $48 \%$ of the boys and $36 \%$ of the girls thought that their weight was 'all right'. 30\% of the boys and $50 \%$ of the girls evaluated themselves as 'too fat' or 'much too fat'. And even in normal weight boys and girls, $21 \%$ and $47 \%$ respectively thought they were 'too fat' or 'much too fat'. These self-evaluations of body weight may be motivated by unrealistic conceptions of healthy body weight and shape. As a result more than three-quarters are using one or more measures to influence their body weight (Table 1).

As may be seen in Table 1, girls are preferentially influencing body weight by changing eating habits while boys tend to use more exercise. As an important side result we found $3.8 \%$ of the girls and $0.8 \%$ of the boys admitted to using vomiting as a measure of weight control. It must be expected that these girls already have an eating disorder or are about to develop one. Since dieting and dietary restraint are considered important risk factors for the development of eating disorders (e.g. bulimia nervosa), there is a remarkable increase in the prevalence of dieting experience with age in girls (Fig. 3).

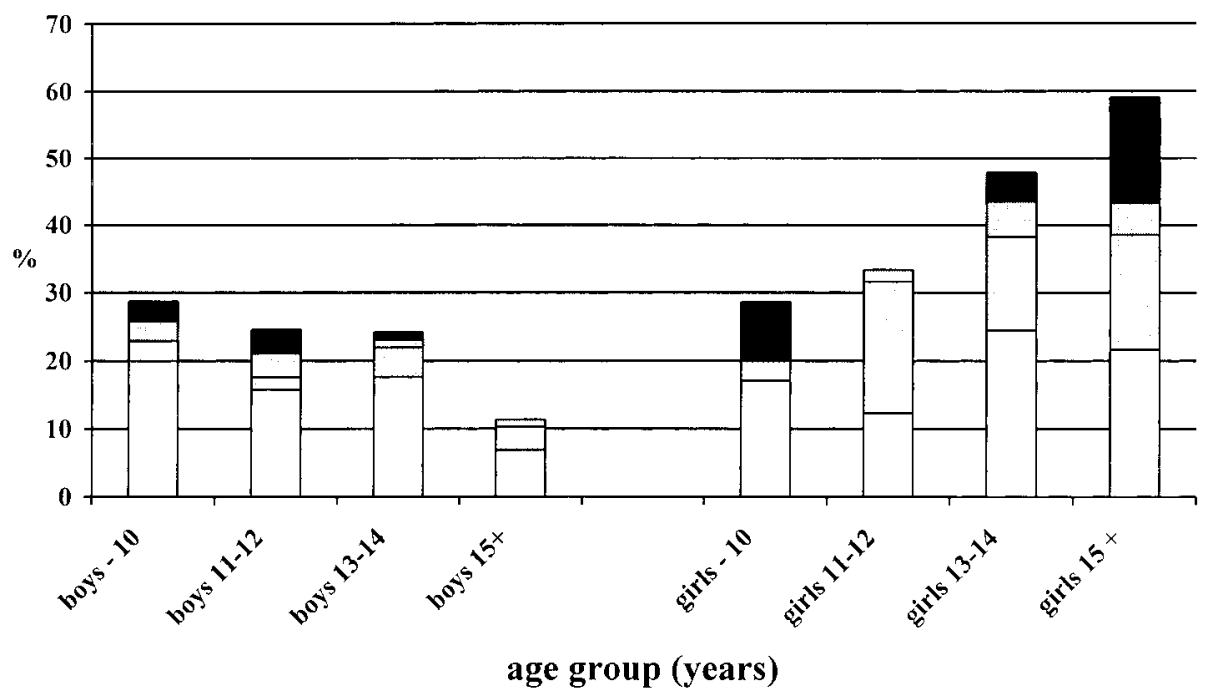

Fig. 3 Diet experience in 7 to 16 year old school children in Hamburg (Germany) (one diet: open bar segments; two-three diets: light shaded bar segment; four-five diets: dark shaded bar segment; more than 5 diets: black bar segment) ${ }^{16}$ 


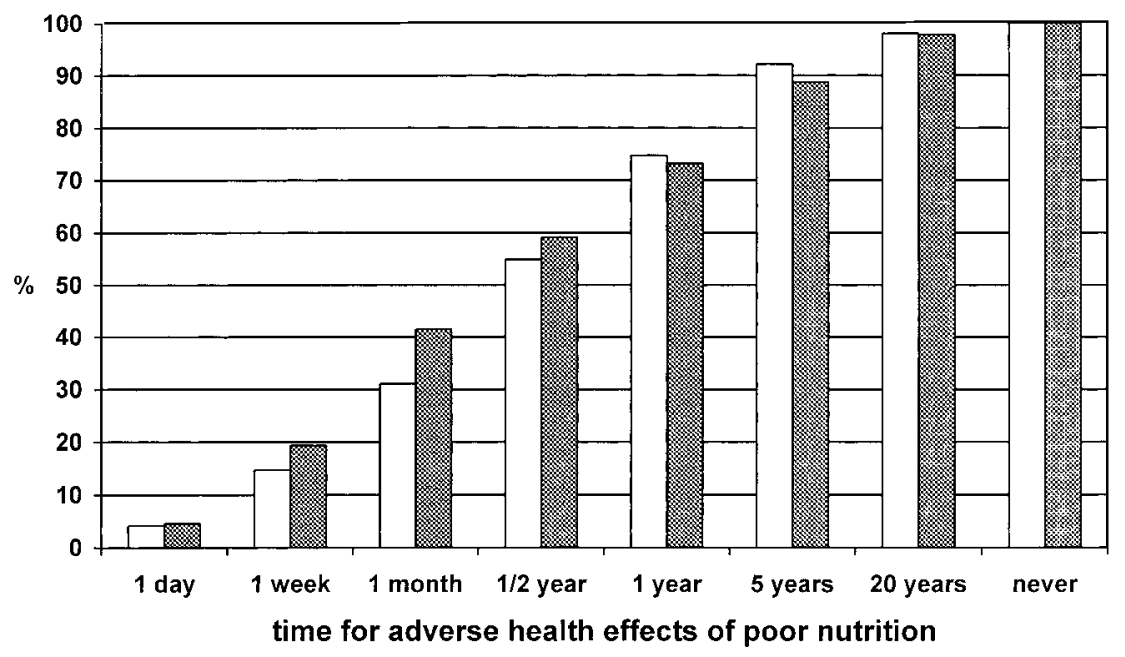

Fig. 4 'How long does it take until poor nutrition has adverse effects for your health?' Cumulative distribution of the answers of 531 girls (open bars) and 456 boys (filled bars) aged 10 to $17^{19}$

\section{Limits of nutrition education}

Nutritional education strategies, especially in younger children, are clearly limited by children's cognitive developmental stages. In particular younger children will not be able to learn the meaning of abstract terms such as energy or nutrients, and their anticipation of future effects is limited to within a few days. In a survey of eating habits and eating attitudes in 10-17-year-old school children in Lower Saxony (Germany) $(\mathrm{N}=987)^{19}$, it was found that the majority of children in this age-group expected adverse health effects of poor nutrition within half a year (Fig. 4). In addition, it has been shown that the knowledge about health or the fattening effects of food does not influence preference in 6- to 10-year-old children $^{20}$. While comprehensive nutrition-education projects over several years have been successful in changing the dietary intake habits of school-children ${ }^{21}$, isolated short-term projects are not likely to change eating behaviour $^{22}$

\section{Opportunities for nutrition education}

In modifying the diet of children, the involvement of the parents is crucial since they greatly influence the choice and availability of food in the home. Nevertheless, it may not be necessary to change attitudes of parents in the first place, since modifying the knowledge, attitudes and behaviour of children regarding their diet and activity patterns is liable to encourage changes in the whole family including the parents and siblings ${ }^{23}$.

An important aspect in nutrition education may be to focus on those aspects of nutrition, which are considered important by the children themselves. In the aforementioned survey of school children in Hamburg ${ }^{16}$, we asked in which aspects of nutrition the participants are interested (Table 2). Fortunately, only less then 10\% confess to having no interest in any nutrition topic. In addition, abstract aspects of nutrition (for example disease, environment or pollution) attract little attention. There is great interest in nutrition topics which have a direct and immediate perceivable benefit for the children: nutrition and better exercise performance, nutrition and improved learning (this is even more pronounced in younger children), and nutrition as it is related to the different aspects of beauty (this is more pronounced in girls than boys).

\section{Conclusions}

In the light of the reviewed findings, a number of conclusions regarding future efforts in nutritional education may be drawn. Successful educational strategies should focus on providing a variety of foods, including the range of nutrient-dense 'healthy' food and encouraging children to taste it. In addition, educational strategies should provide a stable and predictive pattern of social

Table 2 Percentage of 7-16 year-old German school-children interested in different nutrition aspects (multiple answers possible) ${ }^{16}$

\begin{tabular}{lrrr}
\hline & Total & Boys & Girls \\
\hline Exercise performance & $61.0 \%$ & $73.8 \%$ & $50.0 \%$ \\
Better learning & $30.5 \%$ & $31.4 \%$ & $30.4 \%$ \\
Weight loss & $27.8 \%$ & $19.6 \%$ & $36.3 \%$ \\
Healthy skin & $26.1 \%$ & $19.0 \%$ & $34.8 \%$ \\
Beauty & $18.5 \%$ & $11.1 \%$ & $25.9 \%$ \\
Illness & $17.4 \%$ & $16.0 \%$ & $19.3 \%$ \\
Environment & $15.6 \%$ & $16.6 \%$ & $15.2 \%$ \\
Allergies & $11.1 \%$ & $10.0 \%$ & $12.6 \%$ \\
Pollution & $10.7 \%$ & $9.2 \%$ & $12.6 \%$ \\
Other topic & $3.3 \%$ & $3.0 \%$ & $3.7 \%$ \\
No interest & $7.3 \%$ & $9.2 \%$ & $5.2 \%$ \\
\hline
\end{tabular}


eating occasions to promote the social meaning and importance of eating and to enable social learning of food preferences. It also seems to be more promising to establish rituals of meal preparation and eating than to provide cognitive knowledge in nutrition. Educational strategies should communicate the direct perceivable benefits of healthy eating and lifestyle patterns to children, and encourage a positive body image by providing advice and reassurance regarding the range of healthy and acceptable body weights and shapes.

Clearly, nutrition education needs continuous efforts and year-long programmes, not isolated actions. In this context, the influence of children can be utilised to encourage positive changes in dietary habits within the whole family. Lastly, nutrition education requires welldefined and achievable goals with documented evaluations, in order to convince the authorities and sponsors to invest in improved nutrition education programmes.

\section{References}

1 Steiner JE. Facial expressions of the neonate infant indicating the hedonics of food-related chemical stimuli. In: Weiffenbach J. ed. Taste and development: The Genesis of Sweet Preference. (DHEW Publication No. NIH 77-1068). Washington DC: US Government Printing Office, 1977: 173-88.

2 Rosenstein D, Oster H. Differential facial responses to four basic tastes in newborns. Child Dev. 1988; 59: 1555-68.

3 Rozin P. The role of learning in the acquisition of food preferences by humans. In: Shepherd R. ed. Handbook of the Psychophysiology of Human Eating. Chichester: Wiley, 1989: 205-27.

4 Davis C. Self-selection of diets by newly-weaned infants. Am. J. Dis. Child 1928; 36: 651-79.

5 Davis C. Results of the self-selection of diets by young children. Can. Med. Assoc. J. 1939; 41: 257-61.

6 Birch LL. Developmental aspects of eating. In: Shepherd R. ed. Handbook of the Psychophysiology of Human Eating. Chichester: Wiley, 1989: 179-203.

7 Birch LL, Marlin DW. I don't like it; I never tried it: effects of exposure to food on two-year-old children's food preference. Appetite 1982; 4: 353-60.

8 Pliner P. The effects of mere exposure on liking for edible substances. Appetite 1982; 3: 283-90.
9 Duncker K. Experimental modifaction of children's food preferences through social suggestion. J. Abnorm. Social. Psychol. 1938; 33: 489-507.

10 Birch LL. Effects of peer models' food choices and eating behaviors on preschoolers' food preferences. Child Dev. 1980; 51: 489-96.

11 Birch LL, Deysher M. Conditioned and unconditioned caloric compensation: evidence for self-regulation of food intake by young children. Learning \& Motivation 1985; 16: 341-55.

12 Birch LL, McPhee L, Shoba BC, Steinberg L, Krehbiel R. Clean up your plate: effects of child feeding practices on the conditioning of meal size. Learning \& Motivation 1987; 18: $310-7$.

13 Pudel V. Psychologie der Ernährung. Monatsschrift für Kinderheilkunde 1986; 134: 392-6.

14 Pudel V, Westenhoefer J. Ernährungspsychologie. Eine Einfübrung. Göttingen: Hogrefe, 1998.

15 Teuteberg HJ, Wiegelmann G. Der Wandel der Nahrungsgewohnheiten unter dem Einfluß der Industrialisierung. Göttingen: Vandenhoeck \& Ruprecht, 1972.

16 Westenhöfer J. Ernährungsverhalten und Ernährungseinstellungen von Schülern [Eating behaviour and eating attitudes in school children]. Paper presented at the 37th Scientific Congress of the German Nutrition Society, Bonn, 16-17 March 2000.

17 Mast M, Körtzinger I, Müller MJ. Ernährungsverhalten und Ernährungszustand 5-7 jähriger Kinder in Kiel. Aktuelle Ernährungs-Medizin 1998; 23: 282-8.

18 Hill AJ, Draper E, Stack J. A weight on children's minds: body shape dissatisfaction at 9-years old. Int. J. Obes. Relat. Metab. Disord. 1994; 18: 383-9.

19 Westenhöfer J. Beeinflussung des Eßverhaltens durch Gruppenprophylaxe? [Changing eating behaviour by group prevention strategies?]. Oralprophylaxe 1998; 20: 71-6.

20 Deutsche Gesellschaft für Ernährung. ed. Ernährungsbericht 1984. Frankfurt: Druckerei Henrich, 1984.

21 Nader PR, Stone EJ, Lytle LA, Perry CL, Osganian SK, Kelder S, Webber LS, Elder JP, Montgomery D, Feldman HA, Wu M, Johnson C, Parcel GS, Luepker RV. Three-year maintenance of improved diet and physical activity: the CATCH cohort. Child and Adolescent Trial for Cardiovascular Health. Arch. Pediatr. Adolesc. Med. 1999; 153: 695-704

22 Jaensch N, Poggensee G, Westenhoefer J, Hamm M. Empirische Untersuchung der Effektivität von Ernährungserziehung in der Kindertagesstätte. Zeitschrift für Ernährungswissenschaft 1997; 36: 91-2.

23 Basedevant A, Boute D, Borys JM. Who should be educated? Education strategies: Could children educate their parents? Int. J. Obes. Relat. Metab. Disord. 1999; 23(Suppl. 4), S10-3. 